\title{
Genetics of Population Differences in Drug Response
}

\author{
Maulana Bachtiar • Caroline G. L. Lee
}

Published online: 4 July 2013

(c) Springer Science + Business Media New York 2013

\begin{abstract}
Population differences in drug response, including susceptibility to adverse drug reactions, are affected by genetic polymorphisms. Genetic variation frequencies differ among different ethnicities, which may be associated with variation of susceptibility to adverse drug reactions among the different populations. Pharmacogenomics of the population difference in drug response involves the identification of gene variants responsible for these differences in drug response with the aim of using them as predictive markers. However, it is not entirely feasible to characterize all 38 million single-nucleotide polymorphisms (SNPs) in the human genome. Hence, there is a demand to prioritize SNPs for pharmacogenomic analysis, and one emerging trend is through the integration of variables such as information pertinent to the drug and disease pathway, potential functionality of SNPs along the pathway, and the genetics of population differentiation. This review covers background information that is relevant to the genetic basis of population differences in drug response, including the challenges and opportunities ahead.
\end{abstract}

Keywords Pharmacogenomics · Population differentiation · Drug response $\cdot$ Genetics

M. Bachtiar - C. G. L. Lee

Department of Biochemistry, Yong Loo Lin School of Medicine, National University of Singapore, Singapore, Singapore

C. G. L. Lee $(\square)$

Division of Medical Sciences, Humphrey Oei Institute of Cancer Research, National Cancer Centre Singapore, Level 6, Lab 5, 11 Hospital Drive, Singapore 169610, Singapore

e-mail: bchleec@nus.edu.sg

C. G. L. Lee

Duke-NUS Graduate Medical School, Singapore, Singapore

\section{Introduction}

One size does not fit all: drug response is not uniform for everyone. This is the central motivation for personalized medicine. The occurrence of population differences in drug response and the occurrence of adverse drug reactions (ADRs) are common phenomena [1]. In addition, ADRs pose an enormous public health concern because such unintended outcomes of drug response not only exacerbate patient illness, but can also result in a significant economic cost due to ADR-related hospitalizations. In the past years, the cost of ADR-related hospitalization has reached $\$ 136$ billion in the USA alone [2, 3].

Furthermore, population differences in ADR susceptibility have an impact on the drug development process. There is concern with regard to performing clinical trials in a population that is different from the intended target market, especially when the drug is intended for use by individuals of diverse ethnicities. Notably, despite a rising trend of trials conducted in emerging economies, most clinical trials are still performed in developed countries $[4,5]$. Such an approach to drug testing can increase the risk of unforeseen drug-related toxicities in other populations. A drug that is marketed in a specific population should ideally also be tested in that same population during a trial.

However, this process is not entirely straightforward to implement owing, in part, to the high cost of performing clinical trials that cover many populations in multiple regions [6•]. The complexity of performing clinical trials in different ethnic populations from different countries can result in a greater economic burden for both drug developers and patients as it will increase the already astounding cost of drug development. Moreover, such a rigorous trial may also decrease the success rate of marketing drugs that 
are potentially beneficial because of the occurrence of ADR in one or more populations.

One possible solution is to predict potential population differences in drug response at the initial step of drug development. By identifying population groups that are likely to be more susceptible to a potential ADR, the drug developer can avoid a costly and lengthy clinical trial process. At the same time, the approach can expedite entry of potentially beneficial drugs, for the right group of individuals.

\section{Population Differences in Drug Response}

Reports of differences in drug response among different populations are summarized in Fig. 1. Most of these population differences in drug response were reported only after the drug had been released onto the market. In Fig. 1, European descents represent those reported as Caucasian or White, and African descents are those reported as AfricanAmerican, Black, or continental African populations. The East Asian group comprises the Chinese, Japanese, and Korean populations, whereas the Latino group refers particularly to Mexican, Hispanic, or other Latino descents.

Thus far, most reports of differences in the occurrence of ADR/drug response have been between the population of European descent and the population of either African or East Asian descent (Fig. 1), likely owing to drug trials being primarily conducted in the population of European descent before being marketed to the other two major world populations. Examples of some drugs reported to show population differences in response/ADR are discussed below.

5-Fluorouracil, a commonly used cancer chemotherapeutic drug, has been frequently reported to exhibit differences in drug response among different populations. A major side effect associated with this fluoropyrimidinebased drug is the occurrence of hematologic toxicities, including leukopenia and anemia, where differences in prevalence has been reported between the population of European descent and either African-Americans [7-9] or East Asians [8, 10] as well as between those of East Asian descent and Latinos [8] or those of African descent [8] (Fig. 1, blue ribbons). The differences in hematologic toxicities may be due to differences in the activity of the enzyme dihydropyrimidine dehydrogenase [11], where individuals with deficiency in dihydropyrimidine dehydrogenase were reported to be more prone to 5-fluorouracil-induced hematologic toxicities [12].

Warfarin, the most widely prescribed anticoagulant for preventing thrombosis and embolism, is another drug that exhibits significant differences in response among different populations. Despite its effectiveness, treatment with warfarin requires delicate fine-tuning to ensure an adequate yet safe dose for the patient, otherwise the patient will be at high risk of bleeding or the dose of warfarin will be insufficient to protect the patient against thromboembolism. Ethnic differences in the warfarin dose required for effective treatment have been well documented although not often appreciated by clinicians [13]. Significant differences in optimal warfarin dose are observed between East Asians and those of either European or Latino descent as well as between those of European descent and those of either Latino or African descent [14] (Fig. 1, purple ribbons).

Nicotine is another "drug" that displays ethnic differences in its metabolism, which may partially account for the ethnic differences in tobacco-related disease that cannot be fully explained merely by differences in cigarettesmoking behavior [15]. The metabolism of nicotine to cotinine is the major route for the elimination of nicotine; thus, variability in this metabolism may be a possible modulator of nicotine addiction or tobacco-associated disease [16]. The metabolite cotinine can be measured in the serum of individuals, and significant differences in serum cotinine levels are observed between populations of East Asian and European or African descent [16] or between populations of African and Latino descent [17] (Fig. 1 [18-36], red ribbons).

Overall, significant differences in the incidences of response/ADR to a great variety of different drugs, including codeine, vincristine, and $\beta$-blockers, were reported primarily between the population of European descent and the population of Asian or African descent in comparison with other populations (Fig. 1 [18-36], gray ribbons). It is likely that these reports only skimmed the tip of the iceberg and that there are many additional drugs where the response and/or incidence of ADR differs greatly among different ethnic populations but have yet to be carefully examined and reported.

\section{Genetic Factors Affecting Population Differences in Drug Response}

Although drug efficacy is affected by a complex array of elements, which can include environmental and genetic factors, it may not be too feasible to study all the variables simultaneously owing to high heterogeneity among different individuals [37]. Since a person's genetic makeup is a constant variable throughout a person's life; many groups chose to focus on studying the genetic basis of drug response. In the postgenomics era, the term "pharmacogenetics" is broadly used to refer to the study of singlenucleotide polymorphisms (SNPs) or other forms of 
Fig. 1 Circos plot highlighting drugs that exhibit differences in response among two or more populations. The differently colored ribbons joining the different populations represent the specific drugs that show differences in response among more than two different populations. The thickness of a ribbon originating from a specific population indicates the number of populations for which the drug exhibits population differences in response. Gray ribbons represent drugs that were reported to show population differences between only two populations. Numbers denote the literature reference that reported the population difference in response to the specific drug [18-36]. EGFR epidermal growth factor receptor, 5-FU 5-fluorouracil (Color figure online)

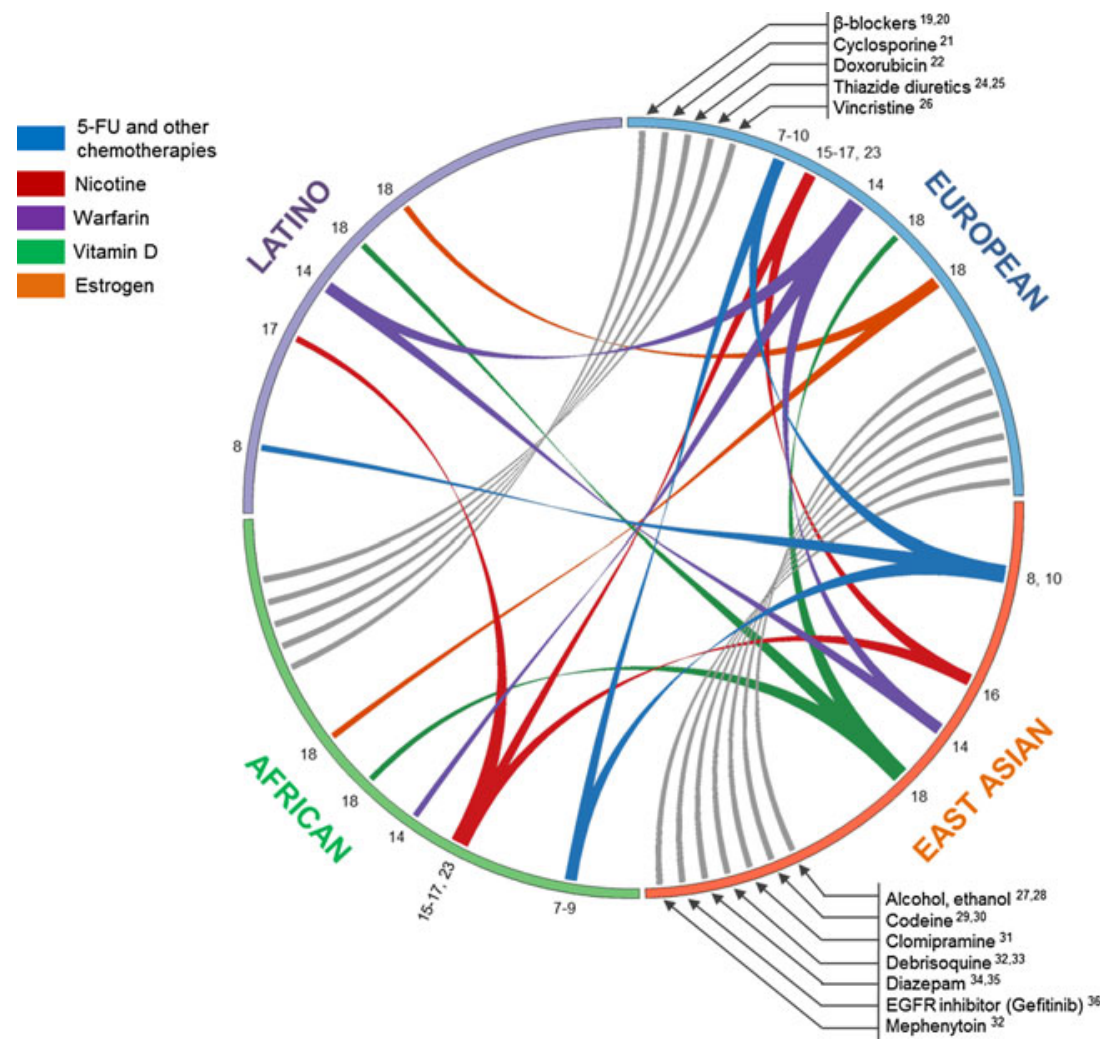

Multigenic Nature Associated with Population Differences in Drug Response: Warfarin as a Case Study

As shown in Fig. 1, there is a considerable population difference in the response to the anticoagulation drug warfarin. Asians would require a significantly lower dose of warfarin compared with Latinos, who in turn are more sensitive to warfarin treatment than individuals of Caucasian descent and African descent [14]. More importantly, the population differences in warfarin response are associated with the genetic polymorphisms in the warfarinresponse pathway.

On the basis of the literature curated in PharmGKB, a highly cited drug pathway database, various genes are involved in the PK and PD processing of the $R$ and $S$ stereoisomers of warfarin [40-42]. The interplay among genes of diverse functional roles will, in turn, affect the drug intracellular concentration, efficacy, and more importantly toxic side effects. Warfarin response is affected, in part, by variants in a gene encoding subunit 1 of the vitamin K epoxide reductase complex (VKORC1) [43••, 44]. Moreover, because warfarin is metabolized in the liver, a number of PK genes, including several metabolizing enzymes such as the cytochrome P450 family of proteins (CYP2C9 and CYP3A4), also play an important role in determining the optimum warfarin dose [43••]. Once they 
have been metabolized in the liver, the resulting metabolites of warfarin are eliminated mostly through the kidney. Interaction of metabolites with the ABCB1 protein, a highly polymorphic membrane transporter, also leads to the possibility of excretion through the bile $[44,45 \bullet]$.

Since the function of many PK and PD genes are affected by genetic variants, SNPs in these genes are frequently associated with differences in drug efficacy and toxicity. Variants in the CYP2C9 and VKORC1 genes have been associated with differential warfarin dose requirements. Individuals carrying the wild-type CYP2C9, or what is commonly referred to as the CYP2C9*1 allele, have normal warfarin PK $[46,47]$. In contrast, a significant decrease in warfarin clearance is observed in individuals who inherit the CYP2C9*2 variant (rs1799853, 430C $>$ T) and in individuals carrying the $* 3$ variant (rs1057910, $1075 \mathrm{~A}>\mathrm{C}$ ) [48-50]. This reduction in warfarin clearance in CYP2C9 "poor metabolizers" can significantly expose patients to warfarin-induced toxicity. A pertinent fact is that because the distribution of CYP2C9 variants is different among populations, with the $* 2$ and $* 3$ alleles observed more frequently in Caucasians than in East Asians and Africans, there is an apparent association between the patients' race and warfarin dosing requirement or toxicity [48, 51-56]. Asians, in general, require a lower dose of warfarin than do other populations.

In addition to SNPs in the CYP2C9 metabolizing gene, the warfarin target gene VKORC1 also affects warfarin PD and is equally important as a determining factor of warfarin response. The VKORC1 promoter SNP that introduces $\mathrm{G}$ to A substitution at a transcription factor binding site (rs9923221, $-1639 \mathrm{G}>\mathrm{A}$ ) is significantly associated with changes in gene expression [57]. Individuals carrying the A allele have lower expression of VKORC1 and require a lower warfarin dose than those inheriting the wild-type $\mathrm{G}$ allele. Similarly to the CYP2C9 variants, this frequency of this functional SNP in VKORC1 is also different among the different populations. The alternative $\mathrm{G}$ allele is predominantly expressed in Asians (more than $90 \%$ ) compared with Caucasians (37\%) and is even rarer in AfricanAmericans $(10 \%)$ [43, 58-60]. Hence, in the case of warfarin, using the patient's race as an initial proxy as a precautionary measure before prescribing the drug is common practice and can be done prior to genotyping SNPs in CYP2C9 and VKORC1. In fact, both the patient's race and genetic information are now used in a number of warfarin dose prediction algorithms, in addition to drug labels generated by the US Food and Drug Administration [61-64].

As evident from the example of warfarin, functional SNPs in drug pathways play significant roles in determining drug response. However, despite this success, established pharmacogenetic markers such as the SNPs found in the CYP2C9 and VKORC1 genes are not common to other drugs. Discovering and validating functional SNPs in drug pathways is not a straightforward process, and is akin to finding a needle in a haystack. Nevertheless, the success in warfarin pharmacogenetics carries a strong message that once discovered; pharmacogenetic markers can improve drug prescription and prevent potential ADR.

In the next section we will discuss strategies to identify potential functional SNPs in drug pathways, highlighting several recent trends of studying population genetics differentiation of SNPs in drug-response genes. If successful, this method can be used to identify the population that has a higher potential of developing ADR to a particular drug, before an individualized pharmacogenetic test can be made available.

\section{Potential Functional Implication of SNPs in Drug-Response Genes}

The most recent release of dbSNP (database build 137) contains more than 38 million SNPs that span the human genome. Therefore, studying the potential effect of each SNP will be an enormous challenge, and there is a growing need to prioritize SNPs on the basis of variables that are informative and at the same time cover all areas of the genome. The tag-SNP approach (in a nutshell, tag SNPs are representative SNPs that are in high linkage disequilibrium with other variants) was adopted by the International HapMap Project and several genome-wide association studies [65, 66]. However, despite serving as "ambassadors" for other SNPs in the region, tag SNPs that are found to correlate with differences in drug response may not necessarily be the causative SNPs important for function of the drug-response gene. Many studies yielded significant SNPs, but they are functionally "blunt" as many of them reside in intergenic or intragenic regions. Since the potential utility of SNPs with no functional insight as pharmacogenetic prediction markers is still questionable, one would still need to identify the potentially functional SNPs in linkage disequilibrium with the tag SNPs and experimentally validate these SNPs, which remains another challenge.

One recent idea is to preselect SNPs using functional annotations and prioritize those that are predicted to be functional. In big-data pharmacogenomics, this method of annotating SNP function before performing in-depth analysis could contribute to reducing the size of the "blind spot" and hence provide a more systemic discovery of pharmacogenetic markers. There are various SNP functional prediction algorithms that have been constructed to identify the putative functional implication of allele substitution as a result of polymorphisms or mutations in DNA 
Fig. 2 Gene regions where single-nucleotide polymorphisms (SNPs) can reside that have functional consequences. $E S E / S$ exonic splicing enhancer/silencer, ISRE intronic splicing regulatory element, miRBS microRNA binding site, $N M D$ nonsensemediated decay, PTM posttranslational modification, TFBS transcription factor binding site
Functional SNPs in drug-response genes
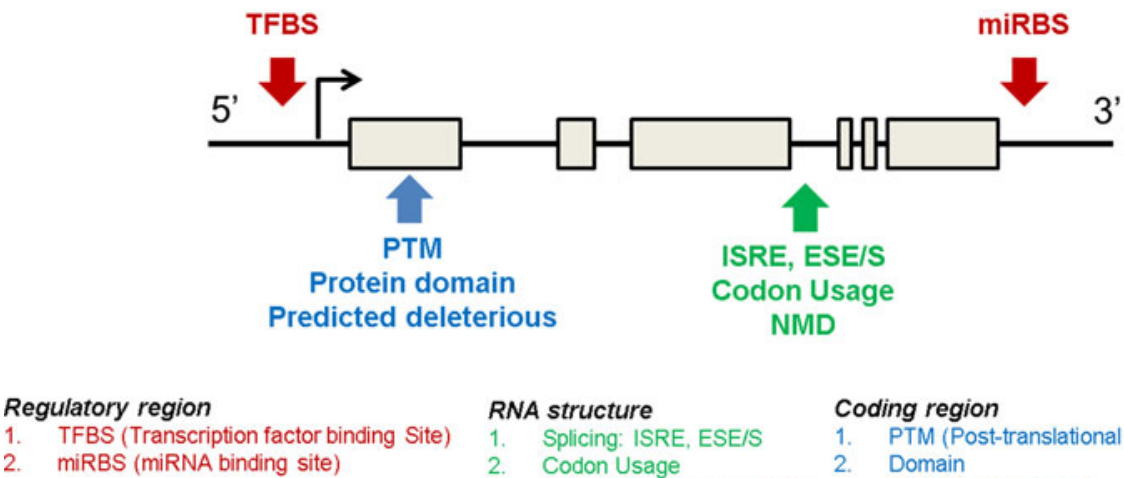

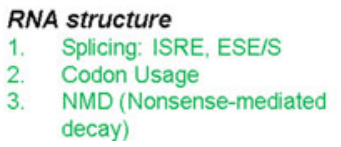

Coding region PTM (Post-translational Modification) Domain Predicted deleterious sequence (Fig. 2). SNPs residing in transcription factor binding sites and exon-intron splicing regulatory regions could potentially affect gene expression by altering the regulation of messenger RNA transcription and splicing activities [67, 68]. On the other hand, nonsynonymous SNPs, which produce amino acid substitution, could affect protein structure and function [45, 69]. SNPs that are positively selected by natural selection forces are also considered to have a certain level of potential impact on gene function [70]. These functional SNPs, when observed in different frequencies, could well serve as future markers for predicting population differences in drug response.

Recently, Wang et al. [71•] integrated these various SNP functional predictions into a one-stop potentially functional SNP portal (http://pfs.nus.edu.sg/). The gene is divided into subregions, such as the $5^{\prime}$ and $3^{\prime}$ untranslated regions, promoter, coding exon, and intron. On the basis of these regions, a SNP potential function is then assessed using various methods, such as sequence motif or evolutionary conservation, to identify the potential impact of a SNP (Fig. 2).

Furthermore, a recent trend in finding functional SNPs in drug-response genes, particularly those that can explain population differences in drug response, is to find SNPs that have significantly different frequencies in different populations. These "population-differentiated SNPs" could serve as predictive markers for interpopulation difference in drug response. Li et al. [72] used this method, albeit they adopt a more "gene level approach" and found significantly more population differentiation in genes important for drug absorption, distribution, metabolism, and excretion. These genes (and the SNPs residing in the gene) could have been subjected to natural or environmental pressures, which can differ in different geographical regions, causing wide variation of allele distribution among populations. We postulate that complemented with potentially functional SNP analysis, this population genetics approach can yield even more promising candidate pharmacogenomic SNPs. Moreover, with the advent of big data from ultra-highthroughput next-generation sequencing that are generated from large number of samples that represent multiple world populations, it is now increasingly feasible to identify such SNPs, including using publicly available data. The challenge will be how to effectively digest this massive amount of information for the specific purpose of finding population-differentiated SNPs that are important in drug response.

\section{Public Resources for Identifying Population- Differentiated Pharmacogenetic Variants}

There are numerous public resources that can be used in pharmacogenomics. This review covers these resources briefly. Population genetics databases contain information such as SNPs and their population allele frequency data, genomic locations, and functional annotations. A drug pathway database on the other hand, provides the necessary information for finding genes that are responsible for a drug PK/PD.

Next-Generation Pharmacogenomics and the Rise of the 1000 Genomes Project

Because the cost of genotyping variants from every individual is high, it is more economical to genotype representative individuals from diverse populations. Since the completion of the Human Genome Project, it has been increasingly feasible to obtain allele frequency information from representative subsets of individuals from different populations or racial backgrounds as opposed to genotyping everyone in a country.

The International HapMap Project pioneered an international-scale project by genotyping individuals originating 
from four populations: Caucasians in Utah, USA, Han Chinese in Beijing, China, Japanese in Tokyo, Japan, and Yoruba African in Ibadan, Nigeria [73]. The same project then expanded to genotyping 1.4 million SNPs in seven additional populations, including Mexican descent [74]. Since the initiation of the International HapMap Project, other groups have also embarked on this same approach of genotyping SNPs from individuals that could presumably represent their population of origin. These include the Singapore Genome Variation Project, which genotyped close to one million SNPs in individuals from three distinct racial groups in Singapore (Malay, Chinese, and Indian), and the Environment Genome Project, which focused on genotyping SNPs found in hundreds of candidate "environmental genes" that are important in apoptosis, cell cycle, DNA repair, drug metabolism, oxidative stress, and several other pathways [75, 76].

More recently, the advent of next-generation sequencing technology has reduced the cost of genome sequencing, and this gave birth to the 1000 Genomes Project. Despite several overlaps in the number of samples used by the International HapMap Project, the 1000 Genomes Project has a different approach. It used next-generation sequencing technology for whole-genome sequencing of 1,092 individuals from various world populations [77••]. This resulted in the identification of significantly more genomic variants such as common SNPs and insertions/deletions, in addition to variants that are observed in low frequency (less than $5 \%$ ). Phase 1 of the 1000 Genomes Project, which released 38 million SNPs (also deposited in dbSNP), provides an abundant wealth of data for pharmacogenomics, particularly as a resource for identifying population-differentiated SNPs that can be used as reference markers in explaining population differences in drug response.

\section{Mining SNPs in Drug-Response Genes}

Literature curation of drug-response genes requires an extensive number of man-hours and may be subjected to a high error rate if it is not conducted consistently. Nevertheless, a drug pathway resource that was constructed on the basis of literature curation performed by a well-established pharmacogenomics initiative is available for public use, and it can be used to find genes that are essential in drug response. The PharmGKB database provides highquality curated drug PK/PD pathway information from which drug-response genes can be obtained for further analysis [41, 42]. In the warfarin example, this information is presented in a curated format that separates genes according to their involvement in the drug PK or PD processes. This pathway information provides additional knowledge with regard to the biological role of the gene of interest as well as its relationship with other genes; hence, it will be useful for finding pharmacogenomic markers that are reported to be associated with differences in drug response.

\section{Using Race as a Proxy: Limitations and Challenges}

The population-based approach of pharmacogenomics has huge translational potential. However, there are limitations to this approach. Questions have been raised with regard to the use of ethnicity as a marker for drug response [78]. Ethnicity or race was originally applied in a social context and often is either self-proclaimed or assigned by an authority [79]. Some have therefore questioned this scientific validity of ethnicity especially in genetic studies, as it could potentially introduce further confounders owing to the different lifestyles adopted by individuals in different racial groups.

However, the high cost that is associated with developing personalized therapy for each individual could deter major pharmaceutical players from adopting truly personalized pharmacogenomics into a drug development pipeline. Therefore, although there is valid reason for the use of race in pharmacogenomics, it is important to note that such apprehension can be overcome by having a good study design. The population-based approach in human genetic studies has been widely accepted by the scientific community. As in the International HapMap Project and the 1000 Genomes Project, the individuals participating are selected from populations that presumably have a low level of genetic admixture. Racial groupings are also usually used as a proxy rather than variables for explaining certain differences in phenotype such as drug response. The identification of population groups that are more susceptible to ADR will allow us to narrow down our selection and perform a personalized pharmacogenetic test in individuals belonging to this high-vulnerability group. The challenge lies in the minimization of the presence of potential confounding variables, particularly those that are related to environmental factors.

\section{Conclusion and Potential Utility of Translational Pharmacogenomics}

Population differences in drug response are widely associated with genetic differentiation that is observed across various populations. The enormous numbers of SNPs from the massive data generated from next-generation sequencing studies provide new layers of both complexity and opportunity. Complexity arises because researchers will have to find the SNPs that are not only differently distributed among populations, but that also have to be functionally important relative to the tens of millions of 
other nonsignificant SNPs. However, discovery efforts will continue. In the future, new opportunities will arise in delivering personalized medicine closer to patients. Translational pharmacogenomics, as in the case of warfarin, can be applied to identify vulnerable individuals using genetic markers that are associated with drug response.

Furthermore, a population-based pharmacogenomic approach to address differences in ADR susceptibility can be used in various settings, ranging from translational research and drug development to clinical application and education of patients. One mission of translational pharmacogenomics is to be able to integrate various approaches, including the use of functional SNPs and populationdifferentiated SNPs, into the drug development pipeline. Currently, most ADR cases are observed only after the drug has been released onto the market. Therefore, the aim is to identify the population that is potentially more susceptible to an ADR in the early phase of drug development before the drug enters the market. If the populations that are potentially vulnerable to the drug under development are identified, potential toxicities during the trial can be avoided if these individuals can be excluded from trials. At the same time, this will help reduce early termination of potentially beneficial drugs and decrease the drug discovery research cost.

Furthermore, physicians have traditionally relied on their experience or the patient's history prior to prescribing a drug. The advent of translational pharmacogenomics will provide a new technology that will transform medicine from an art-centric approach to a stronger knowledge- and science-based approach. Translational pharmacogenomics resources that can provide the necessary information with regard to a patient's predicted response to a particular drug will assist clinicians in prescribing the right drug on the basis of the individual's genetic information. And if this is still too expensive, population genetics data can act as a proxy for the particular individual before a more personalized medicine can be applied. Such information can also be used for educational purposes toward a more informed decision process prior to consumption of a drug. Population pharmacogenomics data will therefore be useful before personalized medicine can become affordable to all.

Acknowledgments This work was supported by an A*STAR-Science and Engineering Research Council (A*STAR-SERC) grant (Diag_043. SERC 112148 0008) as well as by block funding from the National Cancer Centre Singapore and the Duke-NUS Graduate Medical School to Caroline Lee.

Disclosure M. Bachtiar and C.G.L. Lee declare no conflict of interest.

Compliance with Ethical Requirements This article does not contain any studies with human or animal subjects performed by any of the authors.

\section{References}

Papers of particular interest, published recently, have been highlighted as:

- Of importance

•• Of major importance

1. Edwards IR, Aronson JK. Adverse drug reactions: definitions, diagnosis, and management. Lancet. 2000;356(9237):1255-9.

2. Becquemont L. Pharmacogenomics of adverse drug reactions: practical applications and perspectives. Pharmacogenomics. 2009;10(6):961-9.

3. Bond CA, Raehl CL. Adverse drug reactions in United States hospitals. Pharmacotherapy. 2006;26(5):601-8.

4. Thiers FA, Sinskey AJ, Berndt ER. Trends in the globalization of clinical trials. Nat Rev Drug Discov. 2008;7(1):13-4.

5. Karlberg JPE. Globalization of sponsored clinical trials. Nat Rev Drug Discov. 2008;7(5):458-60.

6. - Allison M. Reinventing clinical trials. Nat Biotechnol. 2012;30(1):41-49. This is an industrial perspective on the current trends and challenges in conducting clinical trials. The incremental growth of clinical trials conducted outside developed countries is also highlighted in this article.

7. McCollum AD, Catalano PJ, Haller DG, Mayer RJ, Macdonald JS, Benson AB 3rd, et al. Outcomes and toxicity in AfricanAmerican and Caucasian patients in a randomized adjuvant chemotherapy trial for colon cancer. J Natl Cancer Inst. 2002; 94(15):1160-7.

8. Han HS, Reis IM, Zhao W, Kuroi K, Toi M, Suzuki E, et al. Racial differences in acute toxicities of neoadjuvant or adjuvant chemotherapy in patients with early-stage breast cancer. Eur $\mathbf{J}$ Cancer. 2011;47(17):2537-45.

9. Sanoff HK, Sargent DJ, Green EM, McLeod HL, Goldberg RM. Racial differences in advanced colorectal cancer outcomes and pharmacogenetics: a subgroup analysis of a large randomized clinical trial. J Clin Oncol. 2009;27(25):4109-15.

10. Sekine I, Nokihara H, Yamamoto N, Kunitoh H, Ohe Y, Saijo N, et al. Common arm analysis: one approach to develop the basis for global standardization in clinical trials of non-small cell lung cancer. Lung Cancer. 2006;53(2):157-64.

11. Mattison LK, Fourie J, Desmond RA, Modak A, Saif MW, Diasio RB. Increased prevalence of dihydropyrimidine dehydrogenase deficiency in African-Americans compared with Caucasians. Clin Cancer Res. 2006;12(18):5491-5.

12. Diasio RB, Beavers TL, Carpenter JT. Familial deficiency of dihydropyrimidine dehydrogenase. Biochemical basis for familial pyrimidinemia and severe 5-fluorouracil-induced toxicity. J Clin Invest. 1988;81(1):47-51.

13. Johnson JA. Ethnic differences in cardiovascular drug response: potential contribution of pharmacogenetics. Circulation. 2008;118(13): 1383-93.

14. Dang MT, Hambleton J, Kayser SR. The influence of ethnicity on warfarin dosage requirement. Ann Pharmacother. 2005;39(6): 1008-12.

15. Perez-Stable EJ, Herrera B, Jacob P 3rd, Benowitz NL. Nicotine metabolism and intake in black and white smokers. J Am Med Assoc. 1998;280(2):152-6.

16. Nakajima M, Fukami T, Yamanaka H, Higashi E, Sakai H, Yoshida $\mathrm{R}$, et al. Comprehensive evaluation of variability in nicotine metabolism and CYP2A6 polymorphic alleles in four ethnic populations. Clin Pharmacol Ther. 2006;80(3):282-97.

17. Caraballo RS, Giovino GA, Pechacek TF, Mowery PD, Richter PA, Strauss WJ, et al. Racial and ethnic differences in serum cotinine levels of cigarette smokers: third national health and 
nutrition examination survey, 1988-1991. J Am Med Assoc. 1998;280(2):135-9.

18. Massart F. Human races and pharmacogenomics of effective bone treatments. Gynecol Endocrinol. 2005;20(1):36-44.

19. Comparison of propranolol and hydrochlorothiazide for the initial treatment of hypertension. II. Results of long-term therapy. Veterans Administration Cooperative Study Group on Antihypertensive Agents. J Am Med Assoc. 1982;248(16):2004-11.

20. Materson BJ, Reda DJ, Cushman WC, Massie BM, Freis ED, Kochar MS, et al. Single-drug therapy for hypertension in men. A comparison of six antihypertensive agents with placebo. The Department of Veterans Affairs Cooperative Study Group on Antihypertensive Agents. N Engl J Med. 1993;328(13):914-21.

21. Min DI, Lee M, Ku YM, Flanigan M. Gender-dependent racial difference in disposition of cyclosporine among healthy African American and white volunteers. Clin Pharmacol Ther. 2000; 68(5):478-86.

22. Hershman D, McBride R, Jacobson JS, Lamerato L, Roberts K, Grann VR, et al. Racial disparities in treatment and survival among women with early-stage breast cancer. J Clin Oncol. 2005;23(27):6639-46.

23. Benowitz NL, Perez-Stable EJ, Fong I, Modin G, Herrera B, Jacob P 3rd. Ethnic differences in N-glucuronidation of nicotine and cotinine. J Pharmacol Exp Ther. 1999;291(3):1196-203.

24. Preston RA, Materson BJ, Reda DJ, Williams DW, Hamburger RJ, Cushman WC, et al. Age-race subgroup compared with renin profile as predictors of blood pressure response to antihypertensive therapy. Department of Veterans Affairs Cooperative Study Group on Antihypertensive Agents. J Am Med Assoc. 1998;280(13): 1168-72.

25. Turner ST, Schwartz GL, Chapman AB, Boerwinkle E. C825T polymorphism of the $\mathrm{G}$ protein beta(3)-subunit and antihypertensive response to a thiazide diuretic. Hypertension. 2001;37(2 Pt 2):739-43.

26. Renbarger JL, McCammack KC, Rouse CE, Hall SD. Effect of race on vincristine-associated neurotoxicity in pediatric acute lymphoblastic leukemia patients. Pediatr Blood Cancer. 2008; 50(4):769-71.

27. Dohmen K, Baraona E, Ishibashi H, Pozzato G, Moretti M, Matsunaga $\mathrm{C}$, et al. Ethnic differences in gastric sigma-alcohol dehydrogenase activity and ethanol first-pass metabolism. Alcohol Clin Exp Res. 1996;20(9):1569-76.

28. Chen CC, Lu RB, Chen YC, Wang MF, Chang YC, Li TK, et al. Interaction between the functional polymorphisms of the alcoholmetabolism genes in protection against alcoholism. Am J Hum Genet. 1999;65(3):795-807.

29. Yue QY, Svensson JO, Alm C, Sjoqvist F, Sawe J. Interindividual and interethnic differences in the demethylation and glucuronidation of codeine. Br J Clin Pharmacol. 1989;28(6):629-37.

30. Yue QY, Svensson JO, Sjoqvist F, Sawe J. A comparison of the pharmacokinetics of codeine and its metabolites in healthy Chinese and Caucasian extensive hydroxylators of debrisoquine. Br J Clin Pharmacol. 1991;31(6):643-7.

31. Shimoda K, Jerling M, Bottiger Y, Yasuda S, Morita S, Bertilsson L. Pronounced differences in the disposition of clomipramine between Japanese and Swedish patients. J Clin Psychopharmacol. 1999;19(5):393-400.

32. Bertilsson L, Lou YQ, Du YL, Liu Y, Kuang TY, Liao XM, et al. Pronounced differences between native Chinese and Swedish populations in the polymorphic hydroxylations of debrisoquin and S-mephenytoin. Clin Pharmacol Ther. 1992;51(4):388-97.

33. Nakamura K, Goto F, Ray WA, McAllister CB, Jacqz E, Wilkinson GR, et al. Interethnic differences in genetic polymorphism of debrisoquin and mephenytoin hydroxylation between Japanese and Caucasian populations. Clin Pharmacol Ther. 1985;38(4): 402-8.
34. Kumana CR, Lauder IJ, Chan M, Ko W, Lin HJ. Differences in diazepam pharmacokinetics in Chinese and white Caucasiansrelation to body lipid stores. Eur J Clin Pharmacol. 1987; 32(2):211-5.

35. Ghoneim MM, Korttila K, Chiang CK, Jacobs L, Schoenwald RD, Mewaldt SP, et al. Diazepam effects and kinetics in caucasians and orientals. Clin Pharmacol Ther. 1981;29(6):749-56.

36. Thatcher N, Chang A, Parikh P, Rodrigues Pereira J, Ciuleanu T, von Pawel J, et al. Gefitinib plus best supportive care in previously treated patients with refractory advanced non-small-cell lung cancer: results from a randomised, placebo-controlled, multicentre study (Iressa Survival Evaluation in Lung Cancer). Lancet. 2005;366(9496):1527-37.

37. Evans WE, Relling MV. Pharmacogenomics: translating functional genomics into rational therapeutics. Science. 1999;286(5439): 487-91.

38. Goldstein DB, Tate SK, Sisodiya SM. Pharmacogenetics goes genomic. Nat Rev Genet. 2003;4(12):937-47.

39. Vernot B, Stergachis AB, Maurano MT, Vierstra J, Neph S, Thurman RE, et al. Personal and population genomics of human regulatory variation. Genome Res. 2012;22(9):1689-97.

40. Owen RP, Altman RB, Klein TE. PharmGKB and the International Warfarin Pharmacogenetics Consortium: the changing role for pharmacogenomic databases and single-drug pharmacogenetics. Hum Mutat. 2008;29(4):456-60.

41. Hodge AE, Altman RB, Klein TE. The PharmGKB: integration, aggregation, and annotation of pharmacogenomic data and knowledge. Clin Pharmacol Ther. 2007;81(1):21-4.

42. Thorn CF, Klein TE, Altman RB. PharmGKB: the pharmacogenetics and pharmacogenomics knowledge base. Methods Mol Biol. 2005;311:179-91.

43. •• Limdi NA, Wadelius M, Cavallari L, Eriksson N, Crawford DC, Lee MT, et al. Warfarin pharmacogenetics: a single VKORC1 polymorphism is predictive of dose across 3 racial groups. Blood. 2010;115(18):3827-34. This is a study conducted by the International Warfarin Pharmacogenetics Consortium that involved 4,886 long-term warfarin users from three ethnic groups (Asian, Black, and White). The study confirmed the importance of VKORC1 genotypes with regard to warfarin dosing requirement and reviewed the performance of a previously published pharmacogenetics algorithm.

44. Wadelius M, Sorlin K, Wallerman O, Karlsson J, Yue QY, Magnusson PK, et al. Warfarin sensitivity related to CYP2C9, CYP3A5, ABCB1 (MDR1) and other factors. Pharmacogenomics J. 2004;4(1):40-8.

45. - Wolf SJ, Bachtiar M, Wang J, Sim TS, Chong SS, Lee CG. An update on $\mathrm{ABCB} 1$ pharmacogenetics: insights from a 3D model into the location and evolutionary conservation of residues corresponding to SNPs associated with drug pharmacokinetics. Pharmacogenomics J. 2011;11(5):315-25. This study highlighted the potential functional impact of coding SNPs in the ABCB1 multidrug transporter. It also reviewed various studies that reported the association of $A B C B 1$ SNPs with drug responses.

46. Takahashi $\mathrm{H}$, Echizen $\mathrm{H}$. Pharmacogenetics of warfarin elimination and its clinical implications. Clin Pharmacokinet. 2001;40(8):587-603.

47. Redman AR. Implications of cytochrome P450 2C9 polymorphism on warfarin metabolism and dosing. Pharmacotherapy. 2001;21(2):235-42.

48. Aithal GP, Day CP, Kesteven PJ, Daly AK. Association of polymorphisms in the cytochrome P450 CYP2C9 with warfarin dose requirement and risk of bleeding complications. Lancet. 1999;353(9154):717-9.

49. Margaglione M, Colaizzo D, D’Andrea G, Brancaccio V, Ciampa A, Grandone E, et al. Genetic modulation of oral anticoagulation with warfarin. Thromb Haemost. 2000;84(5):775-8. 
50. Taube J, Halsall D, Baglin T. Influence of cytochrome P-450 CYP2C9 polymorphisms on warfarin sensitivity and risk of overanticoagulation in patients on long-term treatment. Blood. 2000; 96(5):1816-9.

51. Scordo MG, Aklillu E, Yasar U, Dahl ML, Spina E, IngelmanSundberg M. Genetic polymorphism of cytochrome P450 2C9 in a Caucasian and a black African population. Br J Clin Pharmacol. 2001;52(4):447-50.

52. Lee CR, Goldstein JA, Pieper JA. Cytochrome P450 2C9 polymorphisms: a comprehensive review of the in vitro and human data. Pharmacogenetics. 2002;12(3):251-63.

53. Chan SL, Suo C, Chia KS, Teo YY. The population attributable fraction as a measure of the impact of warfarin pharmacogenetic testing. Pharmacogenomics. 2012;13(11):1247-56.

54. Blann A, Hewitt J, Siddiqui F, Bareford D. Racial background is a determinant of average warfarin dose required to maintain the INR between 2.0 and 3.0. Br J Haematol. 1999;107(1):207-9.

55. Kealey C, Chen Z, Christie J, Thorn CF, Whitehead AS, Price M, et al. Warfarin and cytochrome P450 2C9 genotype: possible ethnic variation in warfarin sensitivity. Pharmacogenomics. 2007; 8(3):217-25.

56. Higashi MK, Veenstra DL, Kondo LM, Wittkowsky AK, Srinouanprachanh SL, Farin FM, et al. Association between CYP2C9 genetic variants and anticoagulation-related outcomes during warfarin therapy. J Am Med Assoc. 2002;287(13):1690-8.

57. Wang D, Chen H, Momary KM, Cavallari LH, Johnson JA, Sadee W. Regulatory polymorphism in vitamin $\mathrm{K}$ epoxide reductase complex subunit 1 (VKORC1) affects gene expression and warfarin dose requirement. Blood. 2008;112(4):1013-21.

58. Veenstra DL, You JH, Rieder MJ, Farin FM, Wilkerson HW, Blough DK, et al. Association of Vitamin $\mathrm{K}$ epoxide reductase complex 1 (VKORC1) variants with warfarin dose in a Hong Kong Chinese patient population. Pharmacogenet Genomics. 2005;15(10):687-91.

59. Rieder MJ, Reiner AP, Gage BF, Nickerson DA, Eby CS, McLeod HL, et al. Effect of VKORC1 haplotypes on transcriptional regulation and warfarin dose. N Engl J Med. 2005; 352(22):2285-93.

60. Wadelius M, Chen LY, Lindh JD, Eriksson N, Ghori MJ, Bumpstead S, et al. The largest prospective warfarin-treated cohort supports genetic forecasting. Blood. 2009;113(4):784-92.

61. Gage BF, Eby C, Johnson JA, Deych E, Rieder MJ, Ridker PM, et al. Use of pharmacogenetic and clinical factors to predict the therapeutic dose of warfarin. Clin Pharmacol Ther. 2008;84(3): 326-31.

62. Klein TE, Altman RB, Eriksson N, Gage BF, Kimmel SE, Lee MT, et al. Estimation of the warfarin dose with clinical and pharmacogenetic data. N Engl J Med. 2009;360(8):753-64.

63. Finkelman BS, Gage BF, Johnson JA, Brensinger CM, Kimmel SE. Genetic warfarin dosing: tables versus algorithms. J Am Coll Cardiol. 2011;57(5):612-8.

64. Gage BF, Lesko LJ. Pharmacogenetics of warfarin: regulatory, scientific, and clinical issues. J Thromb Thrombolysis. 2008;25(1): $45-51$.
65. Johnson GC, Esposito L, Barratt BJ, Smith AN, Heward J, Di Genova $\mathrm{G}$, et al. Haplotype tagging for the identification of common disease genes. Nat Genet. 2001;29(2):233-7.

66. International HapMap Consortium. The International HapMap Project. Nature 2003;426(6968):789-96.

67. Fairbrother WG, Yeh RF, Sharp PA, Burge CB. Predictive identification of exonic splicing enhancers in human genes. Science. 2002;297(5583):1007-13.

68. Matys V, Fricke E, Geffers R, Gossling E, Haubrock M, Hehl R, et al. TRANSFAC: transcriptional regulation, from patterns to profiles. Nucleic Acids Res. 2003;31(1):374-8.

69. Adzhubei I, Jordan DM, Sunyaev SR. Predicting functional effect of human missense mutations using PolyPhen-2. Curr Protoc Hum Genet. 2013;Unit 7.20.

70. Tang K, Wong LP, Lee EJ, Chong SS, Lee CG. Genomic evidence for recent positive selection at the human MDR1 gene locus. Hum Mol Genet. 2004;13(8):783-97.

71. - Wang J, Ronaghi M, Chong SS, Lee CG. pfSNP: an integrated potentially functional SNP resource that facilitates hypotheses generation through knowledge syntheses. Hum Mutat. 2011; 32(1):19-24. This article describes the integration of more than 40 different functional SNP prediction algorithms into a one-stop portal. The website at http://pfs.nus.edu.sg makes it easier for users to perform SNP annotation using diverse functional SNP prediction tools.

72. Li J, Zhang L, Zhou H, Stoneking M, Tang K. Global patterns of genetic diversity and signals of natural selection for human ADME genes. Hum Mol Genet. 2011;20(3):528-40.

73. Frazer KA, Ballinger DG, Cox DR, Hinds DA, Stuve LL, Gibbs RA, et al. A second generation human haplotype map of over 3.1 million SNPs. Nature. 2007;449(7164):851-61.

74. Altshuler DM, Gibbs RA, Peltonen L, Dermitzakis E, Schaffner $\mathrm{SF}$, Yu F, et al. Integrating common and rare genetic variation in diverse human populations. Nature. 2010;467(7311):52-8.

75. Teo YY, Sim X, Ong RT, Tan AK, Chen J, Tantoso E, et al. Singapore Genome Variation Project: a haplotype map of three Southeast Asian populations. Genome Res. 2009;19(11):2154-62.

76. Livingston RJ, von Niederhausern A, Jegga AG, Crawford DC, Carlson CS, Rieder MJ, et al. Pattern of sequence variation across 213 environmental response genes. Genome Res. 2004;14(10A):1821-31.

77. •- Abecasis GR, Auton A, Brooks LD, DePristo MA, Durbin RM, Handsaker RE, et al. An integrated map of genetic variation from 1,092 human genomes. Nature. 2012;491(7422):56-65. -This article presented the genome sequencing results of 1,092 individuals from 14 populations involved in the 1000 Genomes Project. Among the variants that were discovered there were 38 million SNPs and 1.4 million insertions/deletions that could be pertinent for finding population-differentiated pharmacogenomic variants.

78. Lee SS. The ethical implications of stratifying by race in pharmacogenomics. Clin Pharmacol Ther. 2007;81(1):122-5.

79. Robertson JA. Constitutional issues in the use of pharmacogenomic variations associated with race. In: Pharmacogenomics. John Wiley \& Sons, Inc.; 2003. p. 291-316. 